\title{
Maria's story - the narrative of a mature international student
}

\author{
Dr Claire Hamshire
}

Manchester Metropolitan University, UK

\section{Dr Kirsten Jack}

Manchester Metropolitan University, UK

\section{Dr Alicia Prowse}

Manchester Metropolitan University, UK

\section{Dr Christopher Wibberley}

Manchester Metropolitan University, UK

\section{Abstract}

This study examines in-depth the experiences of a mature, international student during her first year at university in the UK, in order to explore the different dimensions of her learning transitions. The aim was to gain an in-depth understanding of the factors that influenced a student's on-going development and transformation over their first year; therefore, we adopted a narrative exploratory approach to collecting data.

Maria's narrative is complex and atypical of the majority of the students, yet it details the social and academic challenges that can constitute the first year in higher education (HE), with personal history and expectations having a varying degree of influence on an individual's transition. In line with other research, this narrative shows that students' integration into the academic community, combined with peer support, is crucial if they are going to settle into university life and develop as learners. The transition to HE is an ongoing process and lasts longer than the initial weeks of the formal induction offered by the university.

Keywords: learning; transition; first year; narrative. 


\section{Introduction}

Student success in higher education (HE) is described by Nelson et al. (2012) as being determined by first year student experience, with the initial transition involving multiple factors which influence students' development and transformation at this time. To investigate further how individual students experience this multi-faceted transition, this narrative study explored the experience of an undergraduate physiotherapy student during her first year at a higher education institution (HEI) in England. Drawing on the theories of Tinto $(1987 ; 1993)$ and Yorke $(1999 ; 2000)$ we examined the different dimensions of the transition, with the goal of gaining an in-depth understanding of the factors that influenced this student's learning. Our research focused on the student's experiences and perspectives which were considered to be paramount to identify what we considered to be 'tipping points', where personal factors and experiences combined to lead to either a positive or negative encounter.

The student (known as Maria) who is described in this paper was an international, mature student and as such her narrative represents multiple overlapping transitions. These included her transition to HE and her transition as a mature student back into education; set in the context of her transition to the United Kingdom. Naturally there is a loss of the familiar in all of these transitions and this is compounded by their overlap and impact upon one another. At times Maria's narrative betrays this sense of loss and her vulnerability as she makes the necessary adjustments required for her to negotiate her academic transition within the framework of the others. Her story demonstrates that the transition to HE is not simply a linear procedure, but a gradual process of 'becoming' over time, as she gained new skills and adapted. It is a challenging story of achievements and disappointments, detailing the emotional dimensions of learning that are on-going throughout the first year (see Case et al., 2010). Her story has an upward trajectory yet is interspersed with periods of anxiety as she negotiates her educational journey through the first year.

\section{Background}

The transition into the HE environment has been repeatedly identified as problematic for some students as there is a loss of continuity (see Palmer et al., 2009; Scanlon et al., 
2007; Thomas, 2002; Yorke, 1999), and the literature has identified that a wide variety of personal, social and academic factors can impact on students' learning experiences, probability of academic success, and ultimately on attrition at this time (see Thomas, 2002; Tinto, 1998; Yorke, 1999). Thus the issue of first year student engagement has always been critically significant and has recently become a focus for international discussion (Nelson et al., 2012). For some students the transition to HE is a time of optimism and positive change, but for others it can be difficult and dispiriting (see Field, 2010).

Recent UK research suggests that there are no direct links between a range of factors and a successful transition, however, numerous studies have found that students withdraw from the first year if they feel they are not integrated academically and/or socially (e.g. Harvey et al., 2006). The way in which international students in particular contend with such issues has also been the subject of recent research (e.g. Gu et al., 2010; Zhou et al., 2008). Making a simultaneous transition to a new country requires mastery of language, enculturation to new social norms, and personal development, with, for students, a potential shift in the educational culture for learning. The collective impact of unfamiliar experiences can lead to 'culture-shock' (Zhou et al., 2008) and acculturative stress (Yeh and Inose, 2003) as students contend with language difficulties and social disconnect. Thus Maria epitomised the potential complex, multiple and overlapping nature of a student's transition into HE. Her story hopefully 'brings to life' the factors involved in such a transition.

\section{Methodology}

The purpose of this study was to explore how a first year student made meaning of her transition to HE during the first year at a UK institution. We were interested in the different dimensions of this transition and how personal and external factors impacted upon the learning process. The research was guided by two central questions 1) how do students understand and experience their transition to HE during the first year and 2) how do these experiences illuminate the influence of intrinsic and extrinsic factors? Thus, it was intended to identify how students' experiences and learning developed over time.

Ethics approval was granted by the Faculty Ethics Committee at Manchester Metropolitan University (MMU); and Maria attended for interview once every term throughout her first 
year at university. All of the interviews took place in a meeting room on campus and were arranged at times that were convenient for Maria. In total she attended for three in-depth interviews, each lasting between 45 and 60 minutes in October, January and May.

A narrative prompt question was used at the start of each interview to facilitate Maria's telling of her story, with a request for the story to be considered in chapters or episodes, beginning wherever and however she felt was most appropriate (Gubrium, 1993). The prompt included a request for a detailed narration around the transition to HE. Maria was then allowed to continue her narratives uninterrupted, except for active listening signals from the researcher. When the narrative end was signalled by Maria, with words such as 'Well that's it' or 'That's my story', the researcher began a final questioning phase of the interview where clarification was sought of elements that were unclear. All the interviews were transcribed verbatim.

The holistic nature of narrative inquiry gave Maria an opportunity to focus on key personal events and describe her experiences, rather than following an agenda set by the researchers. Once the data was collected it was then considered that both an inductive and deductive approach to analysis would be adopted. This allowed us to draw deductively on previous studies (such as those carried out by Tinto, 1987; 1993; Yorke, 1999; 2000; which suggested a range of factors that influenced students' on-going development and transformation), whilst also allowing for inductive analysis, to identify emergent themes from the narrative data collected.

The data was analysed using a framework approach (Ritchie and Spencer, 1994) following a phase of familiarisation, indexing and mapping, and interpretation of the data within the framework was carried out (see Ritchie and Spencer, 1994). During this thematic analysis of the interview transcripts, two dimensions were found to be dominant elements of her story - those relating to her social and academic transformation (which impacted upon one another and overlapped). These two dimensions of Maria's story are presented here using narrative fragments to detail her personal development. 


\section{The social dimension}

As a mature, international student, with English as a second language and living off campus, it could be expected that Maria might struggle with the transition into, and construction of, a new social space with the bulk of the cohort, as it was made up mostly of 'school leavers'. She suggested that she was drawn towards the familiar and so started conversations with the other international and mature students, students that she described as 'looking like they might have something in common with me'. She described this in depth:

I initially started to have conversations with international students because then you look at each other and you want to know where they're from... and the mature students because you can relate to them.

As she noted in the third interview, it was these early friendships that were the ones that she still felt most comfortable with at the end of her first year of study. She spent virtually no time with the younger students and described the taught sessions as involving very little mixing, with 'a breakdown of mature and young students, all of the mature students in the front row'.

These friendships with the other international and mature students were the ones that helped her to 'belong' and feel part of the cohort. In talking of these friendships for the first time in the first interview, 'generalised other' terminology was dropped: 'l' had become 'we' and 'us' or 'our' when she talked about classes and study tasks. Thus, Maria had made what we believed were the first vital connections or 'anchorage points' (see Holdsworth and Morgan, 2005) that would be necessary for her to settle into university life.

However, during the second interview (occurring shortly after her return from the Christmas break) she barely mentioned friendships. It was apparent, that at this stage, she considered that friendship had not been a priority for her in the first term. In talking she focused on her academic experience and the grades that she had received for her first assessments. Her husband had a major impact upon her personal development throughout the year and was supportive of her return to HE. He helped her by correcting her grammar, syntax and spelling in her first assessment: 
He makes it more into UK English he says we don't say this like this we say it like that and I think I have less mistakes now because of him being helpful.

Thus, the impression for Maria was that social networking with the other students was very much a secondary benefit to being at HE, with academic success being her real focus. When she alluded to her friendships at all during the second interview, it was in relation to an informal study group that she had formed with a small group of mature students on the programme:

We used to work all the time together in the same group and we were studying, working and practising everything together...so we're pretty much at the same level of understanding.

Thus it would appear from the second interview that the 'social element' of university life was as much, if not more, about peer support than about friendship per se. This view was reinforced during the third interview when she talked at length about the peer support group: 'We had study groups with some of the mates. We used to sit down after class and just discuss and really talk, trying to understand it...so that was good'.

The group consisted of mature and international students and were timed to prepare the students for assessment deadlines:

We don't study at all at the beginning of the unit; we wait until everyone has got a good understanding and then we can sit down and have a nice discussion about everything. If there is something that somebody else doesn't know or the other person doesn't know, there is always, another person that knows and is able to explain on our level, you know...student level.

The network of students Maria worked with was extended by necessity when one of her assignments during the spring term consisted of a group presentation on a set topic, followed by a reflective essay on the presentation. The whole cohort had been randomly divided into groups of three or four for the assignment and Maria found that she was not with any of the mature students that she would normally choose to work and study with: 
We didn't know each other very well at first almost like being very cautious with each other. We were setting out assignments for each other to be able to do by ourselves so that next time we met up...it's all done.

The advantage for Maria of working with a group of students that she would not normally study with, for this assessment, was that she was expanding her social network to include direct entry students 'It's nice to know different people, and work with different people'. However, at her third interview Maria only talked briefly about the group, in terms of her assessment results and how the group had had 'good communication' and been 'respectful to each other'.

\section{The academic dimension}

In all three interviews Maria spoke at length about how she was managing her transition back into education after a break of several years and developing as a learner:

I was like I'm too old...I'm thirty years old I can't possibly be you know... six years without reading a book and not self-learning...so I didn't think I was capable of going back and studying again.

Although she was obviously motivated and prepared to work hard, it seemed she was unprepared for independent study and lacked confidence in her abilities. The pace of work was much faster than she had expected. She stated that:

I had this rushing feeling and I got so stressed the first two weeks trying to keep up. It took a lot for me to keep up and I was right on it...but it took a lot out of me... a lot of time and a lot of effort... a lot of energy.

Initially Maria also felt 'disappointment' with the programme's philosophy of independent learning, which evidently did not match her expectations based on her personal history of didactic teaching. She had been expecting more support, or as she described it 'pampering', in line with her previous educational experiences: 
Well university was exciting at first and then it got a bit overwhelming and then it went easy again. I think just getting used to the rhythm of studying and everything... I'll talk about the course first. I found the course very structured, very good, fast paced a bit more than expected and a bit more self-learning than I expected. In a way I was a bit disappointed I'm the type of person that likes to find out for myself...but I was just expecting a bit more pampering.

Maria also described herself as 'shocked' when she received the brief for the first assessment, she declared that she was 'a bit lost, very lost at first', particularly because she had never written anything in what she called 'British English':

I just want to make sure it's British English. When I saw that written, we want British not American, I just went ahhhh what am I going to do now?

She was disappointed with the result of her first two assessments but was philosophical that she had probably expected too much from herself in terms of academic achievement:

I didn't do as well as I would like to do. I think I put too much pressure on myself to do really well... and what I used to hear was it's only the first year it doesn't count... but for me if I got sixty or eighty it made a big difference.

She continued to talk and gradually revealed that the most disappointing aspect of her assessment feedback were a number of comments about her use of English in her assignment:

I don't think I did well mostly because of my English... mainly just trying to get the information through and make it clear to the reader. It wasn't very good in that way. A few times I found myself contradicting... only because of grammar really...just not using the proper grammar and putting the word not where it's supposed to be and not being very clear.

This feedback led to her lowest point during the first year, as it had a profound effect on her confidence in her ability to write and even speak in English: 
I just wished I had better writing skills to be able to express what I knew because I think I knew good enough to get good marks but I just didn't express that. Since I got the result I think I lost a tiny bit of my confidence and speaking and expressing myself even my English went a bit funny...like trying to speak and it's not coming out.

Lack of confidence in her spoken English had also led to some difficulties with her second assessment, an oral viva exam. Maria had revised hard for this exam and felt that her knowledge was good, but when it came to the actual exam she was extremely nervous and painted a very vivid picture of the scene:

I was so nervous to the point I couldn't stand on my feet. I was so nervous I had to sit down and pant a few times to catch myself because I was shaking, meanwhile I realised I was losing time and then getting more nervous and then I said a few things I knew were wrong, but I didn't correct myself at the time. I didn't even think I had passed to be honest because I didn't think I did well.

\section{Discussion}

The analysis of Maria's narrative outlines the social and academic challenges that students can experience as they develop as learners during their first year in HE. A comment she made at the start of our second meeting, 'University was exciting at first and then it got a bit overwhelming and then it went easy again', probably sums up her experience as she conveys the roller-coaster ride of her transition. It was a statement indicative of some of the joys and successes but also of the difficulties that she had encountered, and gives us an insight into the multifaceted, individual transitions that Maria made during her first year at university.

McGivney (2003) has suggested that non-academic reasons are the primary cause of withdrawal of mature students, and Yeh and Inose (2003) imply that lack of social support can lead to acculturative stress for international students. Mature international students' transitions can therefore be an emotional journey, as they manage both academic and social transformation during a time of considerable adjustment (Yeh and Inose, 2003; Case et al., 2010; Yorke, 2000). Social integration and connectedness are key aspects of 
a successful transition to university and occur when students have developed good relationships and networks with their peers (Yeh and Inose, 2003; Tinto, 1975). Nontraditional students like Maria, who are unfamiliar with the English educational system and out of step with the majority, can find it difficult to develop a social support network and can therefore be most at risk of withdrawal as they adapt to the culture shock (Zhou et al., 2008; Yorke, 1999).

Maria struggled to develop friendships initially and, in terms of social integration, it is apparent that Maria's transition was limited. Although she worked with a peer support group on the lead up to each of her assessments, her main motivation for friendships amongst her peers was to support her academic progress. If her peers were unable to contribute to her academic development, she stopped spending time with them, choosing instead to study with those that could support her learning. However, the more she interacted with the other students in the cohort and developed relationships with staff and her peers, the more she engaged and the more likely she was to continue (see also Bryson and Hardy, 2012). The peer support network that Maria joined within the cohort was pivotal as it gave her an opportunity to build relationships and also eventually a group of friends who supported her. As noted by Yeh and Inose (2003), international students who feel socially connected and satisfied with their social networks are less likely to experience distress.

Maria was also, initially, academically unprepared for the UK HE system and had been out of formal education for some time, clearly articulating her struggle and stress as she adapted during her narrative. Her 'pedagogical adaptation' to the new system was protracted and difficult at times as she struggled with English fluency in both written and oral assessments. As identified by Zhou et al. (2008), this pedagogical adaptation was influenced by both academic cultural differences and different cultures of learning; and a process of adjustment was required during her cross-cultural transition.

It is clear from Maria's narrative that the first year in HE can be an educational journey of learning transitions, and at times students can feel both lost and disengaged from their learning experiences. They may find the material too challenging or too easy, and become distracted by other aspects of their transition. Maria's academic transition was clearly a difficult one. Academic achievement was paramount to her successful transition into university life and it was more difficult to achieve than she had envisaged. Her personal 
educational history was one of structured taught sessions, where she was provided with all the material required, and her initial expectation was that UK HE would offer the same experience. Interestingly she talked at length about course content and assessments but hardly mentioned the academic team or the campus environment, as she focused on gathering knowledge to pass assessments. The first year experience, it would seem, has been one of major adjustments and shifts in perception for Maria in terms of academic expectations.

\section{Conclusion}

To engage with and understand student learning in HE, academic staff need to empathise with students' experiences (Case et al., 2010). Individual narratives give a real insight into the different dimensions of student learning during their transitions and thus may facilitate such empathy. We need to set aside the notion of the 'student learning experience' and focus instead on the multitude of individual transitions that occur during the process of becoming a student.

The purpose of this study was to explore how a student understood and experienced their transition to HE during their first year; and to identify the influence of both intrinsic and extrinsic factors. This paper therefore builds on previous research by highlighting the reality that UK HE institutions have to consider how they can best facilitate students' ongoing transitions throughout the first year and on into subsequent years, particularly for mature international students. Previously UK institutions have tended to confine induction to the first few weeks of the first year but for some students, as exemplified by Maria, the transition will be on-going well after the induction events have finished. Maria's story demonstrates that the transition to HE is not simply a linear procedure (as Gu et al., 2010 also found) but a gradual process of 'becoming' over time, as an individual transforms, gains new skills, and adapts to multiple aspects of culture shock. 


\section{References}

Bryson, C. and Hardy, C. (2012) 'The nature of academic engagement: what the students tell us', in Solomonides, I., Reid, A. and Petocz, P. (eds.) Engaging with Learning. Oxfordshire: Libri Publishing, pp. 25-46.

Case, J.E., Marshall, D. and Linder, C.J. (2010) 'Being a student again: a narrative study of a teachers' experience', Teaching in Higher Education, 15(4), pp. 423-433.

Field, J. (2010) 'Preface', in Ecclestone, K., Biesta, G. and Hughes, M. (eds.) Transitions and learning through the lifecourse. Oxon: Routledge, pp. xvii-xxiv.

Gu, Q., Schweisfurth, M. and Day, C. (2010) 'Learning and growing in a 'foreign' context: intercultural experiences of international students', Compare: A Journal of Comparative and International Education, 40(1), pp. 7-23.

Gubrium, J.F. (1993) Speaking of life: horizons of meaning for nursing home residents. New York: Aldine De Gruyter.

Harvey, L. and Drew, S., with Smith, M. (2006) The first year experience: a literature review for the higher education academy. The Higher Education Academy [Online]. Available at:

https://www.heacademy.ac.uk/sites/default/files/first year experience full report.p df (Accessed: 10 March 2015).

Holdsworth, C. and Morgan, D. (2005) Transitions in context: leaving home, independence and adulthood. Maidenhead: Oxford University Press.

McGivney, V. (2003) Staying or leaving the course. 2nd edn. Leicester: National Institute of Adult Continuing Education.

Nelson, K., Kift, S. and Clarke, J. (2012) 'A transition pedagogy for student engagement and first year learning, success and retention' in Solomonides, I., Reid, A. and Petocz, P. (eds.) Engaging with learning. Oxfordshire: Libri Publishing, pp. 17-144. 
Palmer, M., O'Kane, P. and Owens, M. (2009) 'Betwixt spaces: student accounts of turning point experiences in the first year transition', Studies in Higher Education, 34(1), pp. 37-54.

Ritchie, J. and Spencer, L. (1994) 'Analyzing qualitative data', in Bryman, A. and Burgess, R.G. (eds.) Qualitative data analysis for applied policy research. Routledge: London, pp. 173-194.

Scanlon, L., Rowling, L. and Weber, Z. (2007) 'You don't have like an identity...you are just lost in the crowd': forming a student identity in the first-year transition to university', Journal of Youth Studies, 10(2), pp. 223-241.

Thomas, L. (2002) 'Student retention in higher education; the role of institutional habitus', Journal of Education Policy, 17(4), pp. 423-442.

Tinto, V. (1975) Dropout from higher education: a theoretical synthesis of recent research. Review of Education Research, 45(1), pp. 89-125.

Tinto, V. (1987) Leaving college: rethinking the causes and cures of student attrition. Chicago: University of Chicago press.

Tinto, V. (1993) Leaving college: rethinking the causes and cures of student attrition. $2^{\text {nd }}$ edn. Chicago: University of Chicago press.

Tinto, V. (1998) 'Education, education, education! The vision of lifelong learning in the Kennedy, Dearing and Fryer reports', Oxford Review of Education, 24(4), pp. 89125.

Yeh, C.J. and Inose, M. (2003) 'International students' reported English fluency, social support satisfaction, and social connectedness as predictors of acculturative stress', Counselling Psychology Quarterly, 16(1), pp. 15-28.

Yorke, M. (1999) Leaving early: undergraduate non-completion in higher education. London: Farmer Press. 
Yorke, M. (2000) 'Smoothing the transition into higher education: what can be learned from student non-completion', Journal of Institutional Research, 9(1), pp. 35-47.

Zhou, Y., Jindal-Snape, D., Topping, K. and Todman, J. (2008) 'Theoretical models of culture shock and adaptation in international students in higher education', Studies in Higher Education, 33(1), pp. 63-75.

\section{Author details}

Dr Claire Hamshire is a Senior Learning and Teaching Fellow at Manchester Metropolitan University (MMU). Her research interests include student engagement, attrition and learning transitions.

Dr Kirsten Jack is a Senior Lecturer in Adult Nursing at MMU. Her research interests lie in the development of nurses' emotional self-awareness and the creation of innovative educational methods.

Dr Alicia Prowse is a Principal Lecturer in the Centre for Excellence in Learning and Teaching at Manchester Metropolitan University. Research interests include internationalising the curriculum and global citizenship education, interdisciplinary collaborative inquiry and student motivation.

Dr Christopher Wibberley is a Principal Lecturer in the Faculty of Health, Psychology and Social Care at MMU. His research interests include the narrative explorations of experiences of those providing and receiving health and social care. 